\title{
Qualidade Sinaes para o curso de pedagogia: padrão ou ilusão ${ }^{1}$
}

\section{Sinaes quality standard to pedagogy courses: pattern or illusion?}

\author{
Valdinei Costa Souza ${ }^{2}$
}

\begin{abstract}
RESUMO
Este artigo evidencia a qualidade parametrizada pelo Sistema Nacional de Avaliação da Educação Superior (Sinaes) em seus instrumentos avaliativos e que é usada no processo de orientação da oferta dos cursos de pedagogia. A hipótese de investigação considerou que os resultados exarados pelo Sinaes se baseiam em critérios que não esclarecem o padrão de qualidade desejável para a oferta dos cursos em questão, contribuindo pouco para superar os desafios destacados pelos embates em torno das suas Diretrizes Curriculares Nacionais. Para testar essa hipótese, foram utilizados os dados presentes em uma amostra de fichas de avaliação de cursos in loco, bem como nos instrumentos e resultados avaliativos produzidos pelo Sinaes. A partir de uma perspectiva hermenêutica, a análise dos indicadores e parâmetros efetivamente utilizados pelo Sinaes para avaliar os cursos de pedagogia revelou um padrão de qualidade impreciso, delineando um perfil difuso do que é bom ou adequado para orientar a oferta desses cursos no Brasil.
\end{abstract}

Palavras-chave: qualidade; Sinaes; pedagogia.

\begin{abstract}
This article highlights the quality parameterized by the Brazilian National System for Higher Education Assessment - Sistema Nacional de Avaliação da Educação Superior (Sinaes), considering its assessment tools adequate for the orientation process to offer pedagogy courses in Brazil. The research
\end{abstract}

DOI: $10.1590 / 0104-4060.45326$

1 Pesquisa apoiada pela Coordenação de Aperfeiçoamento de Pessoal de Nível Superior (Capes) por meio do Plano Institucional de Desenvolvimento de Recursos Humanos (PIDRH).

2 Coordenação de Aperfeiçoamento de Pessoal de Nível Superior. Brasília, Distrito Federal, Brasil. Setor Bancário Norte (SBN), Quadra 2, Bloco L, Lote 06, Edifício Capes. CEP: 70040-020. E-mail: valdinei.costa.souza@gmail.com 
hypothesis considered that the results formally recorded by Sinaes are based on criteria that do not account for the desirable quality standards for these courses, contributing little to overcome the challenges around their National Curriculum Guidelines. To test this hypothesis, we used the data present in a sample of on-site courses evaluation formularies, as well as the assessment instruments and results produced by Sinaes. From a hermeneutic perspective, the analysis of indicators and benchmarks actually used by Sinaes to assess the pedagogy courses revealed a pattern of inaccurate quality, outlining a diffuse profile of what is good or desirable to guide the offer of such courses in Brazil.

Keywords: quality; Sinaes; pedagogy.

\section{Introdução}

Este trabalho buscou analisar o padrão de qualidade utilizado pelo Sistema Nacional de Avaliação da Educação Superior (Sinaes) para orientar a oferta dos cursos de pedagogia. Insere-se no quadro de análise advindo da Lei $\mathrm{n}^{\circ} 10.861$, de 14 de abril de 2004 (BRASIL, 2004) que, ao criar o Sinaes, definiu como sua principal finalidade a melhoria da qualidade da educação superior, orientando sua expansão, mas que foi ressignificado pela Portaria Normativa do Ministério da Educação (MEC) n n 40, de 12 de dezembro de 2007 (BRASIL, 2007), que não garantiu organicidade aos indicadores da qualidade que passaram a estruturar o Sinaes, nem o significado concreto da regulação por ele exercida.

O detalhamento operativo do Sinaes, contido na Portaria Normativa ${ }^{\circ} 4$, de 5 de agosto de 2008 (BRASIL, 2008), estabeleceu dois instrumentos para avaliar cursos de graduação: a) o Conceito Preliminar de Curso (CPC), que é um indicador de qualidade gerado a partir de metodologia própria para indicar nota representativa da qualidade do curso; e b) as avaliações in loco, que apuram a nota do curso a partir da opinião de avaliadores. Segundo a referida norma, quando o CPC de um curso é menor que três, ele deve receber a visita de uma comissão para avaliar in loco sua qualidade. A partir dessa visita, a nota de um curso gerada pelo CPC deve ser substituída por aquela indicada pelos avaliadores. No entanto, caso o CPC indique para o curso uma nota igual ou superior a três, esta é automaticamente confirmada e passa a representar o resultado final do processo avaliativo, sem a necessidade de qualquer tipo de avaliação in loco para confirmá-la. (BRASIL, 2008).

Ocorre que as medidas de qualidade utilizadas pelo Sinaes - CPC e avaliação in loco - podem gerar notas e, por consequência, orientações diferentes 
em torno da qualidade de um mesmo curso, sem que se tenham esclarecidos limites, divergências, convergências ou características que justifiquem as diferenças entre elas. Tampouco se tem qualquer explicação conceitual sobre a primazia do CPC frente à avaliação in loco, quando a avaliação é positiva, ou, contraditoriamente, o seu descarte e substituição pelo resultado da avaliação in loco, quando a nota gerada pelo CPC é menor que três.

Além disso, especificamente sobre o instrumento utilizado pelo Sinaes para realizar as avaliações in loco, observa-se ausência de definição objetiva sobre os parâmetros aplicados pelos avaliadores para aferir e sinalizar a qualidade de um curso superior, notadamente na sua dimensão de organização didático-pedagógica, permitindo indagações sobre a validade e fidedignidade dos dados por eles gerados.

Tal constatação, quando contextualizada pela realidade do curso de pedagogia, se mostra ainda mais pertinente em função da pouca clareza sobre como o sistema avaliativo se apropriou das Diretrizes Curriculares Nacionais (DCN) das licenciaturas em foco, assim como dos embates a elas relacionadas, para a definição do padrão que guia, em última instância, o processo de expansão da oferta desses cursos.

Destacando esse contexto, vale pontuar que as DCN da licenciatura em pedagogia foram aprovadas pela Resolução do Conselho Nacional de Educação/ Conselho Pleno (CNE/CPP) nº 1, de 15 de maio de 2006 (BRASIL, 2006) em meio a discussões entre os educadores organizados por meio da Associação Nacional pela Formação de Profissionais da Educação (Anfope), na defesa da ideia da base docente ${ }^{3}$, em contraposição a outros educadores - com destaque para Franco, Libâneo e Pimenta (2007) -, que criticaram essa perspectiva, argumentando que ela traz embutida certa generalidade formativa para o pedagogo como profissional e limitação para a pedagogia como campo teórico-investigativo.

Em linhas gerais, a proposta da base docente ampliou o significado da docência na área de pedagogia, assumindo que esta, além do ato de ministrar aulas, compreende a participação do egresso do curso nas atividades de organização e gestão de sistemas e instituições de ensino. Essa ideia destacou a docência como elemento central na formação do pedagogo, visando superar a dicotomia entre a licenciatura e o bacharelado, então identificada.

Nas discussões em torno da aprovação da proposta da base docente, Libâneo (2006), por exemplo, questionou as condições de um único curso ser

3 Resume a tese do pedagogo como "[...] profissional habilitado a atuar no ensino, na organização e na gestão de sistemas, unidades e projetos educacionais e na produção e difusão do conhecimento [...], tendo a docência como base obrigatória de sua formação e identidade profissional”. (SCHEIBE; AGUIAR, 1999, p. 232). 
capaz de formar com qualidade e, ao mesmo tempo, um profissional para atuar: i) no magistério da educação infantil e dos anos iniciais do ensino fundamental; ii) nas atividades de planejamento, execução, coordenação, acompanhamento e avaliação de tarefas próprias do setor da educação e de experiências educativas não escolares; e iii) na produção e difusão do conhecimento científico-tecnológico do campo educacional, em contextos escolares e não escolares. $\mathrm{O}$ foco das discussões pareceu centrar-se no perfil de formação do aluno egresso do curso de pedagogia e sua possibilidade de contribuir, prioritariamente, para a qualidade da escola básica.

Alimentando essa discussão do ponto de vista da oferta, os relatos de Gatti $(2009,2010)$ sobre a estrutura curricular dos cursos de licenciatura em pedagogia concluíram que estes enfatizavam pouco os conteúdos diretamente afetos à docência - relativos às disciplinas a serem ministradas na educação básica, bem como as suas didáticas. Já do ponto de vista das sinalizações do sistema avaliativo, os resultados apresentados por Souza (2013) destacaram que o Exame Nacional de Desempenho dos Estudantes (Enade) da licenciatura em pedagogia, referente aos anos de 2005, 2008 e 2011, focalizou conhecimentos classificados pelo próprio Enade como gerais, quando era esperado, em função da ideia de docência ampliada, um equilíbrio entre esses e aqueles conhecimentos classificados como específicos das áreas de docência e de gestão educacional.

Assim, ante as limitações constatadas por Gatti $(2009,2010)$ na estrutura curricular da oferta de cursos de pedagogia quatro anos após a aprovação das DCN do curso, associadas às dificuldades de o Sinaes apropriar o conceito da base docente em um dos seus principais componentes, demonstradas por Souza (2013), questionou-se: qual é, então, o padrão de qualidade estabelecido pelo Sinaes para orientar a expansão e a oferta dos cursos de pedagogia?

A busca por respostas a esse questionamento foi direcionada pela hipótese que o Sinaes dispõe de indicadores e parâmetros de qualidade pouco esclarecedores do padrão de referência desejável para a oferta dos cursos de pedagogia, comprometendo o cumprimento da sua finalidade legal de orientar a expansão da oferta dos cursos de graduação em geral, e de pedagogia em específico, com base nas DCN dos cursos.

Para investigar tal hipótese, partiu-se do entendimento de que qualidade é um conceito que pode remeter a significados diferenciados, condicionados a contextos históricos, econômicos, sociais e políticos específicos. Entendeu-se, ainda, que esse conceito possui uma natureza multidimensional, a qual pode remeter a diversos aspectos do campo da educação superior, tais como: cursos, instituições, docentes, processo ensino-aprendizagem, etc. (HARVEY; GREEN, 1993; BERTOLIN, 2007; BURLAMAQUI, 2008; RIOS, 2010; SOUSA, 2009). No entanto, apesar da natureza multidimensional e polissêmica do conceito de 
qualidade, assumiu-se que este pode remeter a um significado específico, quando define indicadores e parâmetros para qualificar determinado objeto como bom ou adequado.

Assim, tendo-se como referência a existência de indicadores e parâmetros para dar significado ao conceito de qualidade, buscou-se identificar aqueles que refletiriam o conceito na realidade concreta das avaliações dos cursos de pedagogia exaradas pelo Sinaes. Nesse processo, utilizou-se como fonte de dados os próprios indicadores e parâmetros que compõem o CPC para os cursos da área em questão nos ciclos avaliativos de 2008 e 2011, bem como aqueles presentes nos relatórios de avaliação in loco e no atual Instrumento de Avaliação de Cursos de Graduação - presencial e a distância. (INEP, 2015).

Para tanto, procedeu-se à escolha de uma amostra sistemática de início aleatório, organizando-se a lista dos 197 cursos de pedagogia com CPC 2008 menor que 3 , em função da região geográfica, organização acadêmica e categoria administrativa das Instituições de Ensino Superior (IES), bem como a evolução ${ }^{4}$ de sua qualidade. Foram escolhidos 40 casos cujos relatórios de visitas foram solicitados ao Instituto Nacional de Estudos e Pesquisas Educacionais Anísio Teixeira (Inep). No entanto, obteve-se o retorno de apenas 12 desses relatórios, todos de IES privadas, em função do universo real de cursos efetivamente visitados. Considerando a redução da amostra de relatórios, mas sendo esses os casos possíveis de serem analisados, foi realizado teste de saturação teórica para sua validação, comprovando-se a suficiência dos dados disponíveis.

Assim, buscou-se sintetizar, por meio de uma análise hermenêutica (MINAYO, 2013), o padrão de referência assumido pelo Sinaes para a oferta com qualidade de cursos de pedagogia, conforme explicitado a seguir.

\section{Avaliações in loco versus CPC: indicadores e parâmetros}

Para fins de síntese dos principais achados da pesquisa, partiu-se dos componentes do CPC, nos termos da Nota Técnica $n^{\circ} 029$, de 15 de outubro de 2012 (INEP, 2012), para destacar os indicadores e parâmetros explícitos no Instrumento de Avaliação de Cursos de Graduação Presencial e a Distância (INEP,

4 Os cursos foram classificados como: a) empenhado - quando aumentaram a nota do CPC 2011 em comparação ao CPC 2008; b) excluídos - cursos com CPC < 3 em 2008 e que ficaram sem conceito (s/c) ou saíram do sistema em 2011; e c) recorrentes - cursos que mantiveram CPC $<3$ em 2011. 
2015) e aqueles subjacentes, presentes no conteúdo das avaliações realizadas in loco referentes ao ano-base 2008, a saber:

a) Nota de Professores Doutores (peso 0,15) e Nota de Professores Mestres (peso 0,075) - esses componentes do CPC assumiram como adequado o simples estoque de conhecimento do docente, certificado pelo diploma de mestre ou doutor. A importância e a necessidade do uso desse estoque de conhecimento na realidade do curso (comumente aferida por meio da produção bibliográfica, técnica e artística qualificada) foram desconsideradas no cálculo desse indicador. Além disso, aspectos como pertinência da área de conhecimento da titulação docente à área do curso, bem como a experiência profissional do professor previstos nos relatórios de avaliação in loco, foram negligenciados na geração do CPC. Na mesma linha, aspectos relativos à experiência e formação da coordenação do curso, presentes no instrumento de visita, não foram considerados na vigente fórmula de cálculo do CPC. Registra-se, ainda, que a mudança no cálculo do CPC fez com que o peso do título de mestre aumentasse de 5\% para 7,5\%. Em contrapartida, o peso do docente titulado com doutorado caiu de $20 \%$ para $15 \%$. Essa mudança favoreceu diretamente as IES privadas, conforme sugerido por Bittencourt et al. (2010), sem que as devidas explicações fossem apontadas na Nota Técnica n ${ }^{\circ}$ 029/2012 (INEP, 2012);

b) Nota de Professores com Regime de Dedicação Integral ou Parcial (peso 0,075) - o significado de qualidade inerente a esse componente não assumiu a dedicação integral como um degrau mais avançado, em relação à dedicação parcial para a qualidade do curso. De certa forma, esse componente, aparentemente, indicou que o mais importante para fazer um bom curso é o tipo do vínculo entre o docente e a instituição, independentemente do tempo que ele dedicou para realizar o trabalho de formação dos alunos na IES. Tal tendência também esteve presente no instrumento de visita in loco, o qual igualmente não fez distinção entre a quantidade de horas dedicadas pelos docentes ao trabalho de formação na IES, tampouco às atividades de pesquisa $\mathrm{e}$ extensão. Assim, tanto na visita avaliativa quanto no cálculo do CPC, o tempo integral não foi considerado como potencialmente ampliador da capacidade de o docente atender de forma mais individualizada e qualitativa um maior número de alunos da instituição;

c) Nota de Infraestrutura (peso 0,075) - o CPC afere a qualidade de infraestrutura do curso por meio da percepção dos alunos sobre a quantidade de equipamentos disponíveis para a realização de aulas 
práticas, apurada durante o Enade. Esse procedimento, a despeito do seu baixo custo de levantamento pelo Inep, pareceu representar uma medida de qualidade pouco útil, restrita ao ponto de vista dos alunos, o qual pode ser tão variado que dificilmente permitiria uma efetiva agregação do significado das respostas processadas. Além disso, do ponto de vista de orientação do sistema, não foi possível estabelecer o que o Sinaes considerou efetivamente, no âmbito do CPC, como uma estrutura suficiente em termos de biblioteca, salas para aulas teóricas, higiene/limpeza ou acessibilidade. Alguns desses aspectos de infraestrutura, inclusive, foram previstos, mesmo que de forma subjetiva, no instrumento de avaliação de cursos in loco, demonstrando a sua relativa importância para o sistema avaliativo. No entanto, a forma de apuração do CPC não os levou em consideração, marcando mais uma das diferenças entre os dois instrumentos utilizados pelo Sinaes para a avaliação de cursos;

d) Nota da Organização Didático-Pedagógica (peso 0,075) - componente que vem sendo aferido durante o Enade, por meio da percepção dos estudantes em relação à estrutura de um plano de ensino. Tal simplificação em sua medida permitiu considerar preocupante o fato de o sistema avaliativo restringir a dimensão de organização didático-pedagógica de um curso à estrutura de um plano de ensino. Não bastasse essa forma inusitada de representar a referida dimensão na fórmula de cálculo do CPC, tal representação foi operacionalizada por meio da simples percepção dos estudantes para mensurar a qualidade do componente em análise, quando, mesmo entre especialistas, há divergência entre concepções ideais para a formação de professores;

e) Nota dos Concluintes no Enade (peso 0,20) - um dos principais componentes para a geração do $\mathrm{CPC}$, as notas de desempenho dos discentes tenderam a agregar pouco na mensuração efetiva da qualidade do curso, notadamente no que se referiu à prova de conhecimentos gerais (que corresponde a $25 \%$ da nota gerada), tendo em vista as competências trazidas pelo próprio estudante e suas motivações para fazer a prova. Conforme discutido por Verhine e Dantas (2008), o principal argumento da crítica a essa variável relacionou-se ao fato de que as condições socioeconômicas individuais são um diferencial e influenciam diretamente na nota Enade, independentemente daquilo que o curso agregou. Além disso, quando se comparou esse componente do CPC com o instrumento de avaliação in loco do curso, observou-se que o desempenho dos alunos no Enade não foi utilizado nas visitas 
avaliativas, mesmo diante da possibilidade de se detalhar os conteúdos trabalhados no curso e sua apreensão pelos alunos;

f) Nota do Indicador de Diferença entre os Desempenhos Observado e Esperado (NIDD) (peso 0,35) - indicador recentemente modificado pelo Inep, com base em uma sofisticada metodologia de ordem estatística, tendo em vista a incorporação da nota do Exame Nacional do Ensino Médio (Enem) em lugar da nota do ingressante do Enade. Há necessidade de uma série histórica para se analisar o impacto das mudanças. Porém, pelo menos conceitualmente, ao considerar a nota do ingressante advinda do Enem, o Sinaes pareceu ter resolvido apenas um problema de custo, economizando os recursos financeiros da aplicação da prova ao grupo de ingressantes. $\mathrm{Na}$ análise da nota técnica, não foi possível encontrar elementos que permitissem superar a crítica feita por Verhine e Dantas (2008), cuja base foi o fato de esse indicador comparar o desempenho de grupos diferentes de alunos que possuíam perfis distintos, seja pelas características pessoais, seja pelas transformações socioeconômicas, agregando pouco sobre a qualidade do curso em função da validade de sua medida. Conforme pôde ser depreendido, o cálculo continuou comparando grupos diferentes de alunos. O desempenho do aluno no Enem, segundo informado pela Nota Técnica $\mathrm{n}^{\circ}$ 029/2012 (INEP, 2012), referiu-se ao Cadastro de Pessoa Física (CPF) do ingressante no curso, e não ao CPF do aluno concluinte, quando aparentemente seria possível comparar os conhecimentos gerais dos concluintes com aqueles trazidos por eles próprios, aproximando-se o item de conhecimentos gerais do Enade a questões do próprio Enem 5 .

Assim, comparando os componentes do CPC com os parâmetros e indicadores utilizados na avaliação in loco de cursos, percebeu-se que, além de fragilidades que ambos têm com instrumentos de medida e julgamento da qualidade da licenciatura em pedagogia, existe ainda certo afastamento na definição dos seus indicadores, notadamente nas dimensões organização didático-pedagógica e infraestrutura, sem que seja possível identificar, a partir dos dados analisados, a dimensão real da relação entre eles. Talvez por isso se tenha observado uma sinalização diferente sobre a qualidade dos cursos de pedagogia, quando se comparam os resultados aferidos pelo CPC com aqueles apresentados pela avaliação in loco, sem que se tenha resolvido qual das duas medidas representa a qualidade assumida pelo Sinaes.

5 O Inep passou a utilizar o desempenho no Enem do próprio aluno concluinte apenas a partir do CPC referente a 2014. 
Para exemplificar essa assertiva, sistematizaram-se os movimentos de subida e descida das notas dos cursos entre os ciclos avaliativos, na Tabela 1. Para tanto, considerou-se a amostra de cursos, cujos relatórios de avaliações in loco foram analisadas. Em relação a esses cursos, comparou-se a nota referente a 2008, estabelecida pela visita avaliativa, e a nota gerada para eles pelo CPC 2011. Como esperado, houve diferença entre a nota de qualidade apurada para um mesmo curso, a despeito do fato de terem sido atribuídas quase ao mesmo momento, em função do curto lapso temporal entre realização das avaliações in loco referentes a 2008 e a geração do CPC 2011.

TABELA 1 - NÚMERO DE CURSOS PESQUISADOS EM FUNÇÃO DA NOTA OBTIDA NA AVALIAÇÃO IN LOCO E DA NOTA NO CPC 2011

\begin{tabular}{|c|c|c|c|c|}
\hline \multirow{2}{*}{ CPC 2011} & \multicolumn{4}{|c|}{$\begin{array}{c}\text { Nota da avaliação in loco, válida como conceito de curso } \\
\text { referente a } 2008\end{array}$} \\
\hline & $\begin{array}{l}\text { cursos com } \\
\text { Nota } 2\end{array}$ & $\begin{array}{l}\text { cursos com } \\
\text { Nota } 3\end{array}$ & $\begin{array}{l}\text { cursos com } \\
\text { Nota } 4\end{array}$ & $\begin{array}{c}\text { total de } \\
\text { cursos }\end{array}$ \\
\hline total de cursos & 1 & 7 & 4 & 12 \\
\hline $\mathrm{CPC}=1$ & - & 1 & - & 1 \\
\hline $\mathrm{CPC}=$ & - & - & 1 & 1 \\
\hline $\mathrm{CPC}=3$ & 1 & 6 & 1 & 8 \\
\hline $\mathrm{CPC}=\mathrm{SC}$ & - & - & 2 & 2 \\
\hline
\end{tabular}

FONTE: INEP [2013]; amostra de relatórios de avaliação de cursos in loco analisados nesta pesquisa. NOTA: $\mathrm{SC}=$ Sem conceito. Esse registro é gerado quando não há insumo para o cálculo do CPC (tais como nota de ingressantes ou concluintes).

Os números revelaram que, a despeito do pouco tempo decorrido entre a apuração de uma medida e a outra (as visitas foram realizadas entre 2010 e 2011), os quatro cursos que receberam nota quatro na avaliação in loco não mantiveram a nota pelas regras de apuração do CPC 2011. Também chamou a atenção o fato de o único curso classificado como de qualidade insuficiente (nota dois) na avaliação in loco ter logrado nota três no CPC 2011, apurado quase que ao mesmo tempo da visita.

Aqui cabe um "parêntese" para entender melhor os fatores presentes nos dados coletados e que explicam por que o curso melhorou a nota no CPC quando a visita apontou uma qualidade inferior. Para tanto, comparou-se o desempenho desse curso nos componentes utilizados para gerar tanto a nota no CPC em 2008 quanto a de 2011. O que se identificou foi a melhoria nas notas de professores doutores, professores com dedicação integral e parcial, além das notas geradas em infraestrutura e organização didático-pedagógica (essas duas últimas em função da significativa guinada estabelecida pelos alunos, que passaram a 
avaliar muito bem a disponibilidade de equipamentos e os planos de ensino do curso). Porém, no que se referiu ao desempenho dos estudantes no Enade e a sua repercussão no NIDD houve, ao contrário, um pequeno decréscimo nas notas apuradas entre 2008 e 2011.

Essa situação específica não permitiu afirmar que houve má-fé da IES ou intenção deliberada de melhorar o seu CPC por meio de informações cadastradas sobre seu corpo docente no Censo da Educação Superior, tampouco que foram dadas orientações expressas aos alunos sobre a importância de melhorar suas percepções em termos da infraestrutura e da organização didático-pedagógica do curso (questões presentes no questionário preenchido durante o Enade e utilizado para gerar a nota do CPC). Por outro lado, sinalizou a desconexão entre os instrumentos utilizados pelo Sinaes para gerar as notas, seja em função da pouca afinidade entre os indicadores presentes nos instrumentos avaliativos - que mensuram um mesmo aspecto de formas diferentes e sem complementaridade -, seja pela precariedade dos indicadores que compõem o CPC - que permitiu considerar como melhoria da qualidade de um curso os rearranjos de fatores periféricos, sem que a qualidade do produto esperado na formação dos futuros pedagogos tivesse sido alterada positivamente.

Fechando o "parêntese" aberto pela situação analisada, os dados sistematizados pela Tabela 1 permitiram observar, ainda, que seis dos sete cursos da amostra qualificados com nota três na avaliação in loco mantiveram a mesma nota no CPC 2011. No entanto, tal correlação quantitativa não foi acompanhada de um padrão qualitativo que contrabalançasse as desconexões anteriormente apontadas. Essa aparente convergência entre as notas apuradas não foi capaz de superar as dúvidas sobre a interconexão entre os dois instrumentos de medida em função da precariedade, já apontada, dos indicadores utilizados pelos instrumentos avaliativos, aliada ao fato de que eles terminam por medir aspectos diferentes: o Enade, que compõe de forma central a avaliação de cursos viabilizada pelo CPC, tem sido completamente ignorado entre os indicadores utilizados pela avaliação in loco.

Nesse sentido, a partir dos dados evidenciados neste estudo, conceitos de cursos atribuídos via CPC não pareceram comparáveis aos conceitos de cursos atribuídos via avaliação in loco. Essas medidas fazem uso de indicadores diferentes e, portanto, tendem a apresentar a realidade também de uma forma diferenciada. Ao contrário do que se poderia esperar, a análise dos dados sinalizou que os critérios utilizados pela avaliação in loco não aprofundaram aspectos considerados pelo CPC, notadamente em torno dos resultados gerados pelo Enade, tampouco estabeleceram articulações com a proposta pedagógica do curso e seus desdobramentos na estrutura curricular, estágios, atividades complementares, corpo docente e infraestrutura, entre outros. A comparação 
dos dois processos avaliativos indicou a existência de repetição das mesmas dimensões de análise tanto no CPC quanto na avaliação in loco, tomadas a partir de indicadores e parâmetros em grande parte diferenciados. Como resultados, observaram-se sinalizações também diferenciadas sobre o que é qualidade, complexificando o sistema avaliativo, sem necessariamente estabelecer um significado claro do que assume como qualidade.

\section{Considerações finais}

Os dados sugerem que, apesar da proposta de avaliação global dos cursos de graduação pelo Sinaes, envolvendo tanto os seus aspectos acadêmicos quanto administrativos, nem os discursos, nem as práticas desses cursos estão sendo adequadamente contempladas pelo processo de aferição de sua qualidade. Por um lado, as discussões em torno das DCN do curso, relativas ao perfil esperado para os egressos, não estão presentes nos critérios avaliativos. Por outro, as definições práticas adotadas pelos cursos para estruturar suas ofertas, também não estão sendo abordadas.

Conforme esclareceram Aguiar et al. (2006, p. 830) “[...] [a docência, nas diretrizes da licenciatura em pedagogia] não é entendida no sentido restrito do ato de ministrar aulas. O sentido da docência é ampliado, uma vez que se articula à ideia de trabalho pedagógico, a ser desenvolvido em espaços escolares e não-escolares". Essa ponderação corroborou o entendimento de que um curso de pedagogia adequado não deve estar circunscrito ao campo das metodologias de ensino e dos conteúdos relativos aos saberes específicos para o exercício da docência na educação infantil e nos anos iniciais do ensino fundamental. Contudo, no que se referiu à dimensão organização didático-pedagógica do Sinaes, constatou-se a falta de sistematização de escalas de medidas para contemplar as orientações presentes nas DCN da licenciatura em pedagogia e, por consequência, de indicadores e parâmetros do Sinaes para orientar adequadamente a qualidade do curso.

Com isso, no seu conjunto, os dados analisados pareceram conduzir ao entendimento de que a qualidade da formação do pedagogo no Brasil revelada pelo Sinaes tem padrões pseudodefinidos. Dois foram os achados principais: i) - a avaliação in loco não estabeleceu parâmetros capazes de identificar os perfis de qualidade relativos aos cinco níveis da escala do Sinaes, seja em função do uso de indicadores e parâmetros pouco claros para a valoração (atribuição de notas) da dimensão organização didático-pedagógica, seja pelo uso de critérios 
de qualidade dissociados de oportunidades de aprendizagens para os alunos, nas dimensões infraestrutura e corpo docente e tutorial; e ii) - não foi possível estabelecer relações entre os critérios utilizados pelo CPC e pelas avaliações in loco para aferir a qualidade das licenciaturas em pedagogia, em função das diferenças no tratamento dos componentes de cada um dos processos, tanto no que se refere aos resultados do Enade, central no primeiro e totalmente desconsiderado no segundo, como também no que se refere à organização didático-pedagógica e à infraestrutura, reduzidas cada uma, no CPC, a uma questão retirada do Questionário do Estudante que integra o Enade.

No caso das avaliações in loco, o Sinaes até conseguiu diferenciar os cursos de pedagogia avaliados com nota dois, qualidade insuficiente, daqueles avaliados com nota três, qualidade suficiente. Porém, houve pouca clareza sobre o significado específico dos perfis gerados por essas notas: não foi possível definir expressões como "interdisciplinaridade adequada" "conteúdo pertinente" ou "referencial de qualidade para ementas e programas de disciplinas". Com isso, os dados não permitiram estabelecer qualquer entendimento sobre o que os avaliadores se referiram quando julgaram o tratamento do conteúdo curricular, as atividades complementares ou o estágio curricular, entre outros aspectos, como suficiente ou insuficiente.

Já no caso do CPC, a mistura de componentes de natureza diversas gerou como resultado um número tão abstrato que pouco contribuiu para sinalizar, por si só, o que o curso tem de bom ou ruim. Apesar de os pesos entre os componentes destacarem a importância do desempenho discente no Enade, uma mesma nota gerada pelo CPC pode indicar tanto que o curso tem espaço para melhorar as características do seu corpo docente quanto a sua organização didático-pedagógica ou ainda em qualquer outro componente ou combinação de componentes desse indicador de qualidade.

No que se referiu às expectativas geradas pelo parecer que subsidiou as DCN de formação de professores (BRASIL, 2001), a qualidade da formação do pedagogo no Brasil revelada pelo Sinaes não aprofundou aspectos em torno do desenvolvimento de aptidões dos egressos para atuar nas modalidades de educação (educação de jovens e adultos, educação especial...), nem analisou os limites e possibilidade dos projetos pedagógicos de atender à expectativa de que os pedagogos formados atuem nesses processos educativos específicos. Adicionalmente, sinaliza pouco sobre a questão dos estágios, sobre os mecanismos institucionalizados para sua realização, suas áreas temáticas, atividades desenvolvidas, entre outros aspectos.

Especificamente sobre o perfil do egresso da licenciatura em pedagogia, o Sinaes, por meio do Enade, revelou que os conteúdos considerados por ele como necessários à formação com qualidade do pedagogo não estão circunscritos 
ao art. $5^{\circ}$ das DCN do curso (BRASIL, 2006), tampouco têm inspiração nos conteúdos sugeridos nas experiências internacionais de avaliação da qualidade de cursos de formação de professores. (OCDE, 2011). O perfil de formação aferido por meio do exame de desempenho discente para o curso em questão não está focado em conteúdos que definem a profissionalidade do pedagogo na condução de classes da educação infantil e anos iniciais do ensino fundamental, tampouco na gestão de espaços escolares e não escolares, conforme ilustrado pelos resultados apresentados por Souza (2013). Essa realidade, aliada ao peso do NIDD que, em linhas gerais, é calculado a partir da comparação do desempenho dos alunos ingressantes no Enem e aqueles apresentados pelo grupo de concluintes na parte de formação geral do Enade (base para formação de qualquer profissional), parece sugerir o entendimento de que um curso de pedagogia de qualidade para o Sinaes tem uma função formativa genérica, sem adentrar nas especificidades da profissão.

$\mathrm{Na}$ análise dos relatórios de visitas realizadas pelo Sinaes para avaliar a qualidade dos cursos foi possível, ainda, destacar que os requisitos legais não se configuraram como uma condição indiscutível para que os cursos sejam qualificados no sistema. Os relatórios das avaliações in loco, apesar de trazerem listados os requisitos legais, não deram qualquer tipo de tratamento a possíveis irregularidades identificadas. Tal situação vem sendo assim explicada pelo instrumento de avaliação in loco:

Estes itens [requisitos legais e normativos] são essencialmente regulatórios, por isso não fazem parte do cálculo do conceito da avaliação, do curso (CC). Os avaliadores apenas farão o registro do cumprimento ou não do dispositivo legal e normativo por parte da instituição para que o Ministério da Educação, de posse dessa informação, possa tomar as decisões cabíveis. (INEP, 2015, p. 41) .

Com isso, ficou subentendido que o Sinaes vem admitindo que um curso de graduação em geral, e de pedagogia em particular, mesmo não obedecendo à legislação, ainda assim poderia ser considerado entre aqueles com perfil de qualidade suficiente, muito boa ou excelente. Aparentemente, é como se as notas resultantes do processo avaliativo não fossem, elas próprias, o principal insumo para a regulação da educação superior no Brasil. Além disso, pontua-se

6 Essa mesma explicação está presente em versões anteriores do Instrumento de Avaliação de Cursos de Graduação - presencial e a distância. 
que não foi encontrado o detalhamento de procedimentos utilizados pelo $\mathrm{Mi}$ nistério da Educação (MEC) para detectar um curso que não está obedecendo à lei, quando este recebe uma avaliação positiva do Sinaes (seja via CPC, seja via avaliações in loco).

Entre os casos analisados neste estudo, encontrou-se, num dos relatórios da avaliação in loco analisados, exemplo concreto dessa realidade. O curso em questão recebeu nota três como resultado do processo de visita avaliativa ao qual foi submetido, embora os avaliadores tivessem encontrado uma desobediência legal em relação às condições de acesso para pessoas com deficiências e/ou mobilidade reduzida. Diante desse fato, seria esperado algum tipo de procedimento de ajuste de conduta/notificação do curso sobre a necessidade de atendimento à legislação. Porém, não houve registro de qualquer tipo de diligência a esse respeito no sistema responsável pelo gerenciamento de informações de regulação e supervisão da educação superior no país. (E-MEC, 2014). Com isso, mesmo desobedecendo a legislação, o curso continuou funcionando sem qualquer tipo de punição.

Por fim, os dados evidenciaram que o Sinaes não vem oferecendo referências objetivas para a organização didático-pedagógica de cursos de pedagogia no Brasil, mas tem fixado as características requeridas para o corpo de docentes e para a infraestrutura, supostamente, para atender a essa organização didático-pedagógica não parametrizada. Adicionalmente, tem sido capaz de hierarquizar os cursos em torno de seu padrão numérico, sem que seja possível identificar o perfil de qualidade dos cursos em todos os níveis da escala, tornando seus critérios pouco esclarecedores sobre o que se espera de um bom curso de pedagogia no Brasil.

\section{REFERÊNCIAS}

AGUIAR, M. Â. da S.; BRZEZINSKI, I.; FREITAS, H. C. L.; SILVA, M. S. P. da; PINO, I. R. P. Diretrizes curriculares do curso de pedagogia no Brasil: Disputas de projetos no campo da formação do profissional da educação. Educação \& Sociedade, Campinas, v. 27, n. 96, p. 819-842, out. 2006.

BERTOLIN, J. C. G. Avaliação da qualidade do sistema de educação superior brasileiro em tempos de mercantilização - Período 1994-2003. 282 f. Tese (Doutorado em Educação) - Universidade do Rio Grande do Sul, Porto Alegre, 2007. 
BITTENCOURT, H. R.; VIALI, L.; RODRIGUES, A. C. de M.; CASARTELL, A. de O. Mudanças nos pesos do CPC e seu impacto nos resultados de avaliação em universidades federais e privadas. Avaliação (Campinas), Sorocaba, v. 15, n. 3, p. 147-166, nov. 2010.

BRASIL. Ministério da Educação. Conselho Nacional de Educação. Parecer $C N E / C P$ no 9/2001, de 8 de maio de 200l. Diretrizes Curriculares Nacionais para a Formação de Professores da Educação Básica, em nível superior, curso de licenciatura, de graduação plena. Brasília, maio 2001. Disponível em: <http://portal.mec.gov.br/cne/arquivos/ pdf/009.pdf>. Acesso em: 04 dez. 2014.

BRASIL. Lei n ${ }^{\circ}$ 10.861, de 14 de abril de 2004. Institui o Sistema Nacional de Avaliação da Educação Superior - Sinaes e dá outras providências. Diário Oficial [da] República Federativa do Brasil, Brasília, 15 abr. 2004. Disponível em: <http://www.planalto.gov. br>. Acesso em: 20 maio 2014.

BRASIL. Ministério da Educação. Conselho Nacional de Educação. Resolução CNE/ $C P n^{\circ} 1$, de 15 de maio de 2006, que institui Diretrizes Curriculares Nacionais para o Curso de Graduação em pedagogia, licenciatura. Brasília, 16 maio 2006. Disponível em: $<$ http:// meclegis.mec.gov.br>. Acesso em: 08 out. 2011.

BRASIL. Ministério da Educação. Portaria Normativa ${ }^{\circ}$ 40, de 12 de dezembro de 2007. Institui o e-MEC, sistema eletrônico de fluxo de trabalho e gerenciamento de informações relativas aos processos de regulação, avaliação e supervisão da educação superior no sistema federal de educação, e o Cadastro e-MEC de Instituições e Cursos Superiores e consolida disposições sobre indicadores de qualidade, banco de avaliadores (Basis) e o Exame Nacional de Desempenho de Estudantes (Enade) e outras disposições. Diário Oficial [da] República Federativa do Brasil, Brasília, 13 dez. 2007. (republicada de forma consolidada em 29 dez. 2010). Disponível em: <http:// meclegis.mec.gov.br>. Acesso em: 20 maio 2014.

BRASIL. Ministério da Educação. Portaria Normativa nº 4, de 05 de agosto de 2008. Regulamenta a aplicação do conceito preliminar de cursos superiores - CPC, para fins dos processos de renovação de reconhecimento respectivos, no âmbito do ciclo avaliativo do Sinaes instaurado pela Portaria Normativa ${ }^{\circ}$ 40, de 2007. Diário Oficial [da] República Federativa do Brasil, Brasília, 06 ago. 2008. Disponível em: $<$ http:// meclegis.mec.gov. br>. Acesso em: 20 maio 2014.

BRASIL. Ministério da Educação. Instituto Anísio Teixeira. Portaria Inep $n^{\circ} 225$, de 26 de julho de 2011. Brasília, 27 jul. 2011. Disponível em: <http://download.inep.gov. br/educacao_superior/enade/legislacao/2011/diretrizes/diretrizes_pedagogia_n_225. pdf>. Acesso em: 12 dez. 2014.

BURLAMAQUI, M. G. B. Avaliação e qualidade na educação superior: Tendências na literatura e algumas implicações para o sistema de avaliação brasileiro. Estudos em Avaliação Educacional, São Paulo, v. 19, n. 39, jan./abr. 2008. 
E-MEC: permite que o cidadão acesse o cadastro de cursos e IES no MEC, bem como informações sobre atos regulatórios, processos e ocorrências no âmbito do Ministério da Educação. 2014. Disponível em: <http://www.emec.mec.gov.br>. Acesso em: 12 dez. 2014.

FRANCO, M. A. S.; LIBÂNEO, J. C.; PIMENTA, S. G. Elementos para a formulação de diretrizes curriculares para cursos de pedagogia. Cadernos de Pesquisa, São Paulo, v. 37, n. 130, p. 63-97, jan./abr. 2007.

GATTI, B. A. Formação de professores para o ensino fundamental: Estudo de currículos das licenciaturas em pedagogia, língua portuguesa, matemática e ciências biológicas. São Paulo: FCC/DPE, 2009. 158 p. (Coleção Textos FCC, 29).

GATTI, B. A. Formação de professores no Brasil: Características e problemas. Educação \& Sociedade, Campinas, v. 31, n. 113, p. 1355-1379, out./dez. 2010.

HARVEY, L.; GREEN, D. Defining quality. Assessment \& Evaluation in Higher Education, London, v. 18, issue 1, p. 9-26, Apr. 1993.

INEP (Instituto Nacional de Estudos e Pesquisas Educacionais Anísio Teixeira). Nota Técnica $n^{\circ}$ 029, de 15 de outubro de 2012. Disponível em: <http://www.inep.gov.br>. Acesso em: 12 dez. 2014.

INEP (Instituto Nacional de Estudos e Pesquisas Educacionais Anísio Teixeira). Tabela_Enade_CPC_2011_retificado_08_12_13.[2013].2013. Disponível em: <http://portal. inep.gov.br/planilhas-enade>. Acesso em: 04 ago. 2013.

INEP (Instituto Nacional de Estudos e Pesquisas Educacionais Anísio Teixeira). Instrumento de avaliação de cursos de graduação - presencial e a distância. Brasília, ago. 2015. Disponível em: <http://www.inep.gov.br>. Acesso em: 20 nov. 2015.

LIBÂNEO, J. C. Diretrizes curriculares da pedagogia: Imprecisões teóricas e concepção estreita da formação profissional de educadores. Educação \& Sociedade, Campinas, v. 27, n. 96, Especial, p. 843-876, out. 2006.

MINAYO, M. C. de S. O desafio do conhecimento: Pesquisa qualitativa em saúde. 13. ed. São Paulo: Hucitec, 2013. 407 p.

OCDE (Organização para a Cooperação e Desenvolvimento Econômico). Building a high-quality teaching profession: Lessons from around the world. Paris: OECD Publishing, 2011. $65 \mathrm{p}$.

RIOS, T. Compreender e ensinar: Por uma docência da melhor qualidade. 8. ed. São Paulo: Cortez, 2010. $158 \mathrm{p}$.

SCHEIBE, L.; AGUIAR, M. Â. Formação de profissionais da educação no Brasil: O curso de pedagogia em questão. Educação \& Sociedade, ano XX, n. 68, p. 220-238, dez. 1999.

SOUSA, J. V. de. Qualidade na educação superior: Lugar e sentido na relação público-privado. Cadernos Cedes, Campinas, v. 29, n. 78, p. 242-256, maio/ago. 2009. 
SOUZA, V. C. Qualidade dos cursos de pedagogia: discurso e prática da base docente. In: REUNIÃO ANUAL DA ANPED, 36., 2013. Anais Eletrônicos... Goiânia, 2013. Disponível em: $<$ http://36reuniao.anped.org.br/pdfs_trabalhos_aprovados/gt08_trabalhos_pdfs/ gt08_2600_texto_valdinei_costa_souza.pdf $>$. Acesso em: 04 dez. 2016.

VERHINE, R.; DANTAS, L. O Enade: Reflexões a partir da completude do ciclo 2004 - 2006. In: SEMINÁRIO INTERNACIONAL DE AVALIAÇÃO DA EDUCAÇÃO SUPERIOR, 1., 2008, Brasília. Anais Eletrônicos... Brasília: MEC, 2008. Disponível em: $<$ http://portal.mec.gov.br/index.php?option=com_content\&view=article\&id=15305 :seminario-internacional-de-avaliacao-da-educacao-superior-2008\&catid=323:orgaos-vinculados\&Itemid=1075>. Acesso em: 24 maio 2012.

Texto recebido em 21 de fevereiro de 2016. Texto aprovado em 15 de agosto de 2016. 
